\title{
Synthesis and Antimicrobial Activity of Novel Benzoxazoles
}

\author{
Mustafa Arisoy $^{\mathrm{a}}$, Ozlem Temiz-Arpaci ${ }^{\mathrm{a}, *}$, Fatma Kaynak-Onurdag ${ }^{\mathrm{b}}$, \\ and Selda Ozgen ${ }^{\mathrm{b}}$ \\ a Ankara University, Faculty of Pharmacy, Department of Pharmaceutical Chemistry, \\ 06100, Tandogan, Ankara, Turkey. Fax: + 90 (312) 2131081. \\ E-mail: temiz@pharmacy.ankara.edu.tr \\ b Gazi University, Faculty of Pharmacy, Department of Pharmaceutical Microbiology, \\ 06330, Etiler, Ankara, Turkey \\ * Author for correspondence and reprint requests \\ Z. Naturforsch. 67c, 466-472 (2012); received October 17, 2011/August 3, 2012
}

A series of 2-( $p$-substituted-benzyl)-5-[[4-( $p$-chloro/fluoro-phenyl)piperazin-1-yl]acetamido]-benzoxazoles were synthesized in need of new compounds for the fight against microbial pathogens. Their structures were elucidated by spectral techniques. These new derivatives, along with previously synthesized 2-( $p$-substituted-benzyl)-5-substituted-benzoxazoles, were evaluated for their antibacterial and antifungal activities against standard strains and drugresistant isolates in comparison with ampicillin, gentamicin sulfate, ofloxacin, vancomycin, fluconazole, and amphotericin B trihydrate. The minimum inhibitory concentration (MIC) of each compound was determined by a two-fold serial dilution technique. The compounds were found to possess a broad spectrum of antimicrobial activities with MIC values of $32-256 \mu \mathrm{g} / \mathrm{ml}$. Although standard drugs were more active against the pathogenes employed in this study, the activities of the new benzoxazoles and reference drugs against drug-resistant isolates of the microorganisms were largely similar.

Key words: Benzoxazoles, Antibacterial Activity, Antifungal Activity

\section{Introduction}

The fight against bacterial infections has resulted in the development of a wide variety of antibiotics. After years of misuse of antibiotics, bacteria have become antibiotic-resistant, resulting in a potential global health crisis. Infectious diseases due to Gram-positive bacteria such as methicillin-resistant Staphylococcus aureus (MRSA), vancomycin-resistant Enterococcus faecalis (VREF), and penicillin-resistant Streptococcus pneumoniae (PRSP) are the leading causes of morbidity and mortality today (Moustafa et al., 2004). Besides, during the past 20 years an increase in invasive fungal infections, particularly in immunosuppressed patients, has been observed which are now considered to be causes of morbidity and mortality as well. Therefore, there is still need for new antifungal and antibacterial agents (Andriole, 1999). Benzoxazoles are the structural isosteres of natural nucleotides and interact easily with the biopolymers so that they constitute an important class of heterocyclic compounds with antimicrobial and antibiotic activity (Prudhomme et al., 1986; Sarma et al., 2003; Haansuu et al., 2001;
Temiz-Arpaci et al., 2002, 2005; Yildiz-Oren et al., 2004; Tekiner-Gulbas et al., 2007). The benzoxazole derivative calcimycin (Fig. 1) is a carboxylic polyether antibiotic from a strain of Streptomyces chartreusis (NRRL 3882). It was found to be very active against Gram-positive bacteria including some Bacillus and Micrococcus strains (Prudhomme et al., 1986).

In the last seven years we have described the synthesis of different derivatives of some 2,5-disubstituted benzoxazoles and their in vitro antimicrobial activity against some Gram-positive and Gram-negative bacteria and the fungus Candida albicans (Temiz-Arpaci et al., 2005, 2008; Oksuzoglu et al., 2007, 2008; Arisoy et al., 2008). In the present study, a new series of $2-(p$-substituted-benzyl)-5-[[4-( $p$-chloro/fluoro-phenyl)piperazin-1-yl]acetamido]-benzoxazoles, $\mathbf{3 - 1 2}$, has been synthesized as target compounds and evaluated for their antibacterial and antifungal activities, along with previously synthesized benzoxazole derivatives, against standard strains and drug-resistant isolates in comparison with several reference drugs. Furthermore, structure-activity relationships (SAR) are discussed. 


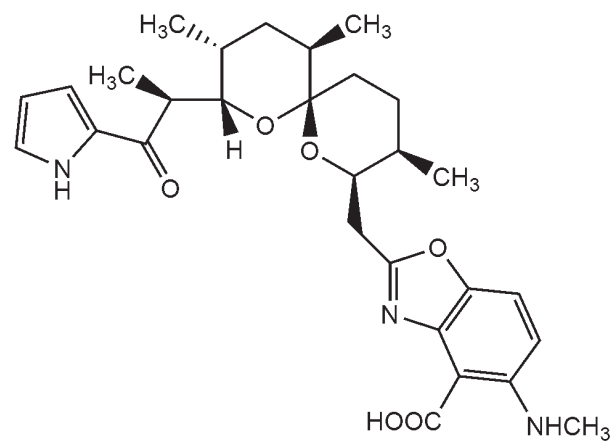

Fig. 1. Chemical structure of calcimycin.

\section{Results and Discussion}

We aimed at enhancing the antimicrobial activity of 2,5-disubstituted benzoxazoles by expanding the substituent at the C-5 position. To this end, some new 2-( $p$-substituted-benzyl)-5-[[4-( $p$ chloro/fluoro-phenyl)piperazin-1-yl]acetamido]benzoxazoles, 3-12, were synthesized. The synthetic route for preparation of the target compounds is shown in Scheme 1. First the 5-amino2-( $p$-substituted-benzyl)-benzoxazoles $\quad \mathbf{1 a}-\mathbf{1 e}$ were obtained by heating appropriate acids with 2,4-diaminophenol in polyphosphoric acid (PPA). The amides $2 \mathbf{a}-\mathbf{2 e}$ were then obtained through the reaction of 5-amino-2-( $p$-substituted-benzyl)benzoxazoles with chloroacetyl chloride. In the last step the newly synthesized compounds 3-12 were prepared from the amides by treating them with 4-substituted piperazine derivatives. Their structures were elucidated by mass and NMR spectroscopy, respectively, and their purity was analysed through elemental analysis (Table I). The compounds were also evaluated for their antimicrobial activity along with previously synthesized benzoxazole derivatives (Table II).

Compounds 3-12 had same but low antibacterial activity against the bacteria $S$. aureus and E. faecalis with minimum inhibitory concentration (MIC) values between $128-256 \mu \mathrm{g} / \mathrm{ml}$ which are higher than those of the standards ampicillin, gentamicin, ofloxacin, and vancomycin. Nevertheless, these compounds had enhanced activity against the drugresistant isolates of these bacteria, in the range of a MIC value of $64 \mu \mathrm{g} / \mathrm{ml}$ of ampicillin against MRSA (Staphylococcus aureus isolate resistant to methicillin), except for compound $\mathbf{8}$ which was as potent as gentamicin and vancomycin against the isolate of E. faecalis with a MIC value of $32 \mu \mathrm{g} / \mathrm{ml}$. The new benzoxazole derivatives possessed low antibacterial activity against $B$. subtillis and its drugresistant isolate with MIC values of $128 \mu \mathrm{g} / \mathrm{ml}$.

Compounds 3-12 provided moderate activity against $P$. aeruginosa and its drug-resistant isolate with MIC values of $64 \mu \mathrm{g} / \mathrm{ml}$. They had the same activity like ofloxacin against the drug-resistant isolate of $P$. aeruginosa. All derivatives $3-32$ possessed low activity against the standard strains of $E$. coli and $K$. pneumoniae in comparison with the standard drugs and, in general, the activities of the previously synthesized derivatives 13-32<smiles>[R7]c1ccc(Cc2nc3cc(N)ccc3o2)cc1</smiles>

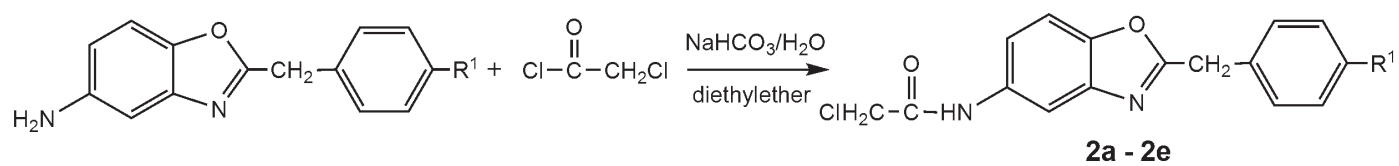

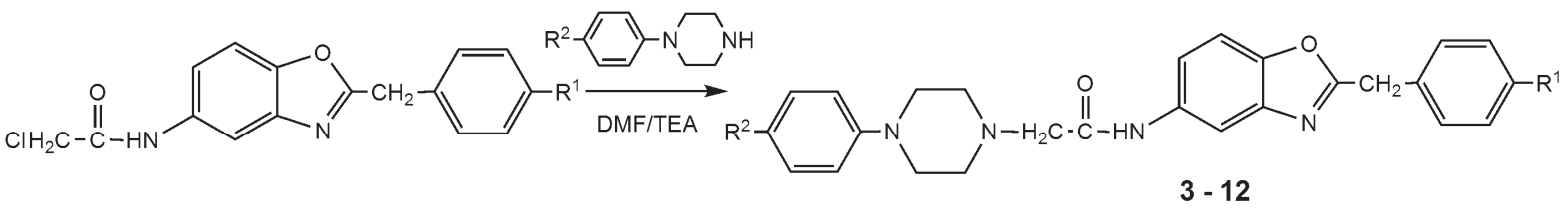

$\mathrm{R}^{1}: \mathrm{Cl}_{1} \mathrm{CH}_{3}, \mathrm{H}, \mathrm{Br}, \mathrm{F}$

$\mathrm{R}^{2}: \mathrm{Cl}, \mathrm{F}$

Scheme 1. Synthetic pathway of the target compounds $\mathbf{3}-\mathbf{1 2}$. 


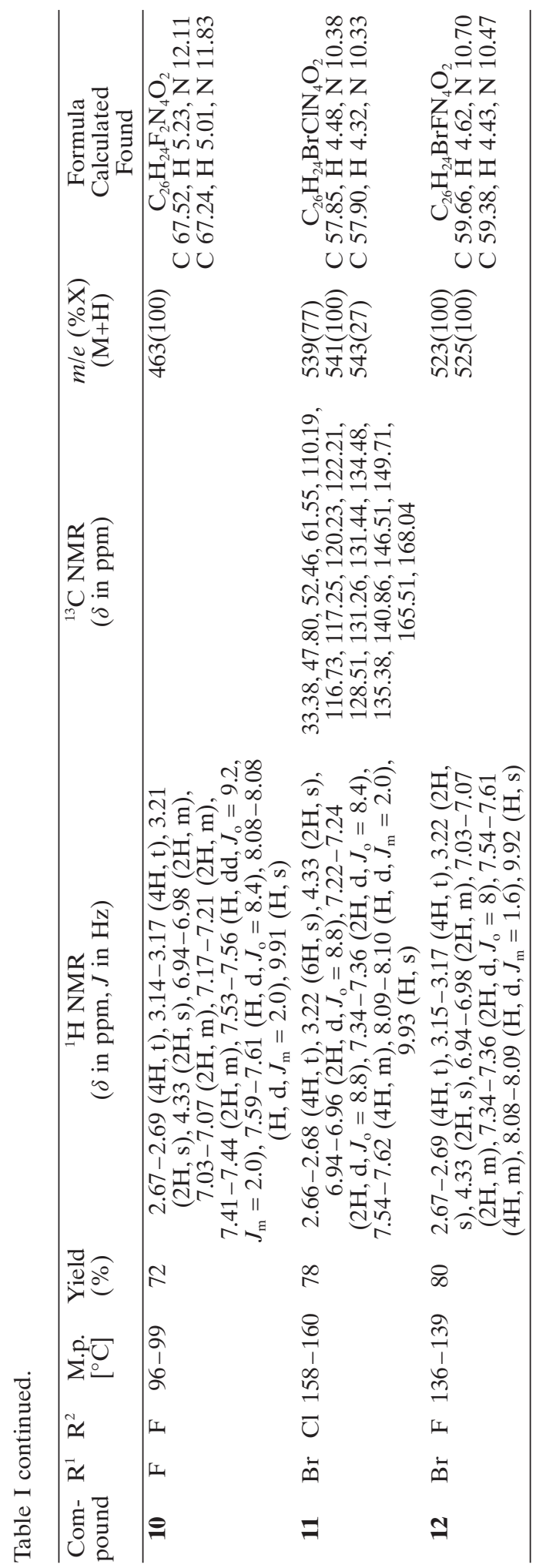

were higher than those of the new benzoxazoles. The activities of all compounds against the isolates of these bacteria were as high as those of ampicillin and better than those of gentamicin.

The comparison of the activities of the new benzoxazoles with those of the antifungal drugs fluconazole and amphothericin B showed that the newly synthesized compounds were less inhibitory against $C$. albicans and C. krusei with MIC values between $64 \mu \mathrm{g} / \mathrm{ml}$ and $256 \mu \mathrm{g} / \mathrm{ml}$.

It can be concluded that different substituents at the C-5 position of the 2-( $p$-substitutedbenzyl)-benzoxazole nucleus provided similar antimicrobial activity. The activities of standard drugs against standard strains were higher than those of the benzoxazole derivatives, whereas in most cases the MIC values of standard drugs against the isolates of the bacteria were quite similar to those of the benzoxazoles.

\section{Experimental}

\section{Materials and methods}

Chemicals and solvents were purchased from Sigma-Aldrich (Taufkirchen, Germany) and Fisher Scientific (Pittsburgh, PA, USA) and were used without further purification. Silica gel $\mathrm{HF}_{254}$ chromatoplates $(0.3 \mathrm{~mm})$ were used for thin layer chromatography (TLC), and the mobile phase was chloroform/methanol $(10: 0.5, \mathrm{v} / \mathrm{v})$ for compounds 3-12. Melting points (M.p.) were recorded on a Stuart Scientific SMP 1 (Bibby Scientific Limited, Staffordshire, UK) instrument and are uncorrected. NMR spectra were recorded on a Varian (Palo Alto, CA, USA) Mercury $400 \mathrm{MHz}$ NMR spectrometer in $\mathrm{CDCl}_{3}$ or dimethylsulfoxide (DMSO$d_{6}$ ); tetramethylsilane (TMS) was used as an internal standard. The mass spectra were recorded on a Waters (Milford, MA, USA) ZQ Micromass LC-MS spectrometer using the $\operatorname{ESI}(+)$ method. Elemental analyses were performed on an LECO 932 CHNS (St. Joseph, MI, USA) instrument and were within $\pm 0.4 \%$ of theoretical values.

Materials used in the microbiology study were; Mueller Hinton agar (MHA) (Merck, Darmstadt, Germany), Mueller Hinton broth (MHB) (Merck), Sabouraud dextrose agar (SDA) (Merck), RPMI-1640 medium with L-glutamine (SigmaAldrich), 3-(N-morpholino)-propane-sulfonic acid (MOPS) (Sigma-Aldrich), 96-well microplates (BD, Franklin Lakes, NJ, USA), transfer pipette (Eppendorf, Hamburg, Germany), am- 
Table II. In vitro antimicrobial activities of newly and previously synthesized benzoxazole derivatives in comparison with reference drugs.

\begin{tabular}{|c|c|c|c|c|c|c|c|c|c|c|c|c|c|c|c|c|}
\hline \multirow[t]{3}{*}{ Compound } & \multirow[t]{3}{*}{$\mathbf{R}^{1}$} & \multirow[t]{3}{*}{$\mathrm{R}^{2}$} & \multicolumn{14}{|c|}{$\operatorname{MIC}[\mu \mathrm{g} / \mathrm{ml}]$} \\
\hline & & & \multicolumn{6}{|c|}{ Gram-negative bacteria } & \multicolumn{6}{|c|}{ Gram-positive bacteria } & \multicolumn{2}{|c|}{ Fungi } \\
\hline & & & E.c. & E.c.* & K.p. & K.p.* & P.a. & P.a.* & S.a. & S.a.* & E.f. & E.f.* & B.s. & B.s.* & C.a. & C.k. \\
\hline 3 & $(p-\mathrm{Cl}) \mathrm{Ph}-\mathrm{N}$ & $\mathrm{Cl}$ & 128 & 128 & 128 & 128 & 64 & 64 & 128 & 64 & 128 & 64 & 128 & 128 & 64 & 64 \\
\hline 4 & $(p-\mathrm{F}) \mathrm{Ph}-\mathrm{N}$ & $\mathrm{Cl}$ & 128 & 128 & 128 & 128 & 64 & 64 & 128 & 64 & 128 & 64 & 128 & 128 & 64 & 64 \\
\hline 5 & $(p-\mathrm{Cl}) \mathrm{Ph}-\mathrm{N}$ & $\mathrm{CH}_{3}$ & 128 & 128 & 128 & 128 & 64 & 64 & 128 & 64 & 128 & 64 & 128 & 128 & 128 & 64 \\
\hline 6 & $(p-\mathrm{F}) \mathrm{Ph}-\mathrm{N}$ & $\mathrm{CH}_{3}$ & 128 & 128 & 128 & 128 & 64 & 64 & 256 & 64 & 128 & 64 & 128 & 128 & 64 & 64 \\
\hline 7 & $(p-\mathrm{Cl}) \mathrm{Ph}-\mathrm{N}$ & $\mathrm{H}$ & 128 & 128 & 128 & 128 & 64 & 64 & 256 & 64 & 128 & 64 & 128 & 128 & 128 & 64 \\
\hline 8 & $(p-\mathrm{F}) \mathrm{Ph}-\mathrm{N}$ & $\mathrm{H}$ & 128 & 128 & 128 & 128 & 64 & 64 & 128 & 64 & 128 & 32 & 128 & 128 & 128 & 64 \\
\hline 9 & $(p-\mathrm{Cl}) \mathrm{Ph}-\mathrm{N}$ & $\mathrm{F}$ & 128 & 128 & 128 & 128 & 64 & 64 & 256 & 64 & 128 & 64 & 128 & 128 & 256 & 64 \\
\hline 10 & $(p-\mathrm{F}) \mathrm{Ph}-\mathrm{N}$ & $\mathrm{F}$ & 128 & 128 & 128 & 128 & 64 & 64 & 128 & 64 & 128 & 64 & 128 & 128 & 64 & 64 \\
\hline 11 & $(p-\mathrm{Cl}) \mathrm{Ph}-\mathrm{N}$ & $\mathrm{Br}$ & 128 & 128 & 128 & 128 & 64 & 64 & 128 & 64 & 128 & 64 & 128 & 128 & 128 & 256 \\
\hline 12 & $(p-\mathrm{F}) \mathrm{Ph}-\mathrm{N}$ & $\mathrm{Br}$ & 128 & 128 & 128 & 128 & 64 & 64 & 128 & 64 & 128 & 64 & 128 & 128 & 128 & 64 \\
\hline 13 & $\mathrm{O}$ & $\mathrm{Cl}$ & 128 & 128 & 128 & 128 & 64 & 64 & 128 & 64 & 128 & 64 & 128 & 128 & 64 & 64 \\
\hline 14 & $\mathrm{CH}_{2}$ & $\mathrm{Cl}$ & 64 & 128 & 64 & 128 & 64 & 64 & 32 & 64 & 128 & 64 & 128 & 128 & 128 & 64 \\
\hline 15 & $\mathrm{CH}_{3}-\mathrm{N}$ & $\mathrm{Cl}$ & 64 & 128 & 128 & 128 & 64 & 64 & 128 & 64 & 128 & 64 & 128 & 128 & 64 & 64 \\
\hline 16 & $\mathrm{Ph}-\mathrm{N}$ & $\mathrm{Cl}$ & 64 & 128 & 64 & 128 & 64 & 64 & 128 & 64 & 128 & 64 & 128 & 256 & 64 & 64 \\
\hline 17 & $\mathrm{O}$ & $\mathrm{CH}_{3}$ & 128 & 128 & 128 & 128 & 64 & 64 & 128 & 64 & 128 & 64 & 128 & 128 & 32 & 64 \\
\hline 18 & $\mathrm{CH}_{2}$ & $\mathrm{CH}_{3}$ & 64 & 128 & 64 & 128 & 64 & 64 & 64 & 64 & 64 & 64 & 128 & 128 & 64 & 64 \\
\hline 19 & $\mathrm{CH}_{3}-\mathrm{N}$ & $\mathrm{CH}_{3}$ & 64 & 128 & 64 & 128 & 64 & 64 & 64 & 64 & 128 & 64 & 128 & 256 & 64 & 64 \\
\hline 20 & $\mathrm{Ph}-\mathrm{N}$ & $\mathrm{CH}_{3}$ & 64 & 128 & 64 & 128 & 64 & 64 & 128 & 64 & 128 & 64 & 128 & 256 & 64 & 64 \\
\hline 21 & $\mathrm{O}$ & $\mathrm{H}$ & 128 & 128 & 128 & 128 & 64 & 64 & 128 & 64 & 128 & 64 & 128 & 128 & 128 & 64 \\
\hline 22 & $\mathrm{CH}_{2}$ & $\mathrm{H}$ & 64 & 128 & 64 & 128 & 64 & 128 & 128 & 64 & 128 & 64 & 128 & 128 & 128 & 64 \\
\hline 23 & $\mathrm{CH}_{3}-\mathrm{N}$ & $\mathrm{H}$ & 128 & 128 & 128 & 128 & 64 & 128 & 256 & 64 & 128 & 64 & 128 & 128 & 128 & 64 \\
\hline 24 & $\mathrm{Ph}-\mathrm{N}$ & $\mathrm{H}$ & 32 & 128 & 64 & 128 & 64 & 128 & 128 & 64 & 128 & 64 & 128 & 128 & 64 & 64 \\
\hline 25 & $\mathrm{O}$ & $\mathrm{Br}$ & 64 & 128 & 128 & 128 & 64 & 128 & 128 & 64 & 128 & 64 & 128 & 128 & 128 & 64 \\
\hline 26 & $\mathrm{CH}_{2}$ & $\mathrm{Br}$ & 64 & 128 & 128 & 128 & 64 & 128 & 128 & 64 & 128 & 64 & 128 & 128 & 128 & 64 \\
\hline 27 & $\mathrm{CH}_{3}-\mathrm{N}$ & $\mathrm{Br}$ & 64 & 128 & 64 & 128 & 64 & 128 & 128 & 64 & 128 & 64 & 128 & 128 & 128 & 64 \\
\hline 28 & $\mathrm{Ph}-\mathrm{N}$ & $\mathrm{Br}$ & 64 & 128 & 128 & 128 & 64 & 128 & 256 & 64 & 128 & 64 & 128 & 128 & 128 & 64 \\
\hline 29 & $\mathrm{O}$ & $\mathrm{F}$ & 32 & 128 & 64 & 128 & 64 & 64 & 128 & 64 & 128 & 64 & 128 & 128 & 128 & 64 \\
\hline 30 & $\mathrm{CH}_{2}$ & $\mathrm{~F}$ & 128 & 128 & 128 & 128 & 64 & 64 & 128 & 64 & 128 & 64 & 128 & 128 & 128 & 64 \\
\hline 31 & $\mathrm{CH}_{3}-\mathrm{N}$ & $\mathrm{F}$ & 32 & 128 & 128 & 128 & 64 & 64 & 128 & 64 & 128 & 64 & 128 & 128 & 128 & 64 \\
\hline 32 & $\mathrm{Ph}-\mathrm{N}$ & $\mathrm{F}$ & 64 & 128 & 64 & 128 & 64 & 128 & 128 & 64 & 128 & 64 & 128 & 128 & 64 & 64 \\
\hline Ampicillin & & & 2 & 128 & 2 & 128 & n.d. & n.d. & 2 & 64 & 2 & 2 & 0.5 & 0.5 & n.d. & n.d. \\
\hline $\begin{array}{l}\text { Genta- } \\
\text { micin }\end{array}$ & & & 0.5 & $>512$ & 0.5 & 256 & 0.5 & $>512$ & 0.125 & 32 & 4 & 32 & 0.25 & 0.125 & n.d. & n.d. \\
\hline Ofloxacin & & & $<0.0625$ & 64 & 0.125 & 0.5 & 8 & 64 & 0.25 & 0.25 & 1 & 4 & 0.125 & 0.25 & n.d. & n.d. \\
\hline $\begin{array}{l}\text { Vanco- } \\
\text { mycin }\end{array}$ & & & n.d. & n.d. & n.d. & n.d. & n.d. & n.d. & 1 & 1 & 1 & 32 & n.d. & n.d. & n.d. & n.d. \\
\hline $\begin{array}{l}\text { Fluco- } \\
\text { nazole }\end{array}$ & & & n.d. & n.d. & n.d. & n.d. & n.d. & n.d. & n.d. & n.d. & n.d. & n.d. & n.d. & n.d. & 1 & 32 \\
\hline $\begin{array}{l}\text { Ampho- } \\
\text { thericin B }\end{array}$ & & & n.d. & n.d. & n.d. & n.d. & n.d. & n.d. & n.d. & n.d. & n.d. & n.d. & n.d. & n.d. & 0.25 & 2 \\
\hline
\end{tabular}

n.d., not determined (microbiological assays were not performed due to following reasons: $P$. aeruginosa is naturally resistant to ampicillin; Gram-negative bacteria employed in the study are naturally resistant to vancomycin; vancomycin is not used in the therapy against B. subtilis; antibacterial drugs were not assayed against fungi; antifungal drugs were not assayed against bacteria).

E.c., E. coli ATCC 25922; E.c.*, E. coli isolate (ESBL); K.p., K. pneumoniae RSKK 574; K.p.*, K. pneumoniae isolate (ESBL); P.a., P. aeruginosa ATCC 25853; P.a.*, P. aeruginosa isolate (resistant to gentamicin); S.a., S. aureus ATCC 29213; S.a.*, S. aureus isolate (MRSA); E.f., E. faecalis ATCC 29212; E.f.*, E. faecalis isolate (VRE); B.s., B. subtillis ATCC 6633; B.s.*, B. subtillis isolate (resistant to ceftriaxon); C.a., C. albicans ATCC 10231; C.k., C. krusei ATCC 6258. 
picillin (Mustafa Nevzat Pharmaceuticals, Istanbul, Turkey), gentamicin sulfate (Paninkret, Pinneberg, Germany), ofloxacin (Zhejiang Huangyan East Asia Chemical, Huangyan, Zhejiang, China), vancomycin (Mayne Pharma, Salisbury South, SA, Australia), fluconazole (Sigma-Aldrich), amphotericin B trihydrate (Riedel de Haen, Seelze, Germany), DMSO (Riedel de Haen).

Microorganisms used in the assay were; Klebsiella pneumoniae isolate [extended $\beta$-lactamase spectrum (ESBL)], Escherichia coli isolate (ESBL), Enterococcus faecalis isolate [resistant to vancomycin (VRE)], Bacillus subtillis isolate (resistant to ceftriaxon), Pseudomonas aeruginosa isolate (resistant to gentamicin), and Staphylococcus aureus isolate [resistant to methicillin (MRSA)], $K$. pneumoniae RSKK 574, E. coli ATCC 25922, E. faecalis ATCC 29212, P. aeruginosa ATCC 25853 , B. subtillis ATCC 6633, S. aureus ATCC 29213, Candida albicans ATCC 10231, and Candida krusei ATCC 6258. Reference strains and clinical isolates were obtained from Gazi University, Faculty of Pharmacy, Department of Pharmaceutical Microbiology, Culture Collection (Ankara, Turkey) and Gazi University Hospital, Microbiology Laboratory (Ankara, Turkey), respectively.

General procedure for the preparation of 5-amino2-(p-substituted-benzyl)-benzoxazoles (1a-1e)

The 5-amino-2-( $p$-substituted-benzyl)-benzoxazoles were synthesized by heating $0.02 \mathrm{~mol} 2,4$-diaminophenol hydrochloride with $0.02 \mathrm{~mol} p$-substituted phenyl acetic acid in $25 \mathrm{~g}$ polyphosphoric acid (PPA) and stirring for 1-2 $\mathrm{h}$. At the end of the reaction period, the residue was poured into an ice/water mixture, and the solution was neutralized with $10 \% \mathrm{NaOH}$. The resulting precipitate was filtered, washed with distilled water, dissolved in boiling ethanol with $0.2 \mathrm{~g}$ charcoal, and filtered off. Then distilled water was added slowly to the filtrate in order to stimulate crystallization. The crude compounds $\mathbf{1 a}-\mathbf{1 e}$ were obtained by filtering and drying the crystalline material (Yildiz-Oren et al., 2004; Oksuzoglu et al., 2007, 2008; TemizArpaci et al., 2008; Arisoy et al., 2008).

\section{General procedure for the preparation of} 5-(2-chloroacetamido)-2-(p-substituted-benzyl)benzoxazoles $(\mathbf{2 a}-\mathbf{2 e})$

Chloroacetyl chloride $(0.02 \mathrm{~mol})$ was added over a period of $1 \mathrm{~h}$ to a stirred, ice-cooled mixture of 5-amino-2-( $p$-substituted-benzyl)-benzoxazole $(0.02 \mathrm{~mol})$, sodium bicarbonate $(0.02 \mathrm{~mol})$, diethyl ether $(40 \mathrm{ml})$, and water $(20 \mathrm{ml})$. The mixture was continuously stirred overnight at room temperature and filtered. The precipitate was washed with water, $2 \mathrm{M} \mathrm{HCl}$, and water, respectively, and the crude product was obtained by drying needles in vacuo (Arisoy et al., 2008).

\section{General procedure for the preparation of} 2-(p-substituted-benzyl)-5-[[4-(p-chloro/fluorophenyl)piperazin-1-yl]acetamido]-benzoxazoles $(3-12)$

0.002 mol 5-(2-chloroacetamido)-2-( $p$-substituted-benzyl)-benzoxazole were added to 0.002 mol $N$-(p-chloro/fluoro-phenyl)piperazine and 0.006 mol triethylamine (TEA) solution in $3.5 \mathrm{ml}$ $\mathrm{N}, \mathrm{N}$-dimethylformamide (DMF). The mixture was stirred at room temperature for $24 \mathrm{~h}$. At the end of the reaction time, $5 \mathrm{ml}$ toluene were added, and the reaction medium was evaporated under reduced pressure. The residue was dissolved in chloroform and washed three times with $5 \% \mathrm{NaOH}$ and then once with distilled water. The solution was dried over anhydrous sodium sulfate, filtered, and evaporated under reduced pressure. The residue was dissolved in ethyl acetate and precipitated by adding $n$-hexane. If necessary, recrystallization was performed. Crystalline material was dried in vacuo. All the compounds 3-12 were prepared as original products. Their structures were supported by spectral data. The mass and ${ }^{1} \mathrm{H}$ NMR spectra, respectively, and the results of the elemental analyses agree with those of the proposed structures. ${ }^{13} \mathrm{C}$ NMR spectra were obtained only for compounds $3,6,8, \mathbf{1 1}$. Physical and spectral data of the compounds are reported in Table I.

\section{Microbiological assays}

For microbiological assays, ampicillin, gentamicin sulfate, ofloxacin, vancomycin, fluconazole, and amphotericin B trihydrate were dissolved in appropriate solvents recommended by the Clinical and Laboratory Standards Institute (CLSI) guidelines (CLSI, 2006, 2008). Stock solutions of the test compounds were prepared in DMSO.

Bacterial susceptibility testing was performed according to the guidelines of CLSI M100-S18 (CLSI, 2008). MHB was added to each well of the microplates. The bacterial suspensions used for inoculation were prepared at $10^{5} \mathrm{CFU} / \mathrm{ml}$ by 
diluting fresh cultures at McFarland 0.5 density $\left(10^{7} \mathrm{CFU} / \mathrm{ml}\right)$. Two-fold diluted solutions of the compounds were inoculated with bacterial suspensions of $10^{5} \mathrm{CFU} / \mathrm{ml}(10 \mu \mathrm{l}$ inoculum per well to give $10^{4} \mathrm{CFU} / \mathrm{ml}$ bacteria in the wells), and the microplates were incubated overnight at $37^{\circ} \mathrm{C}$.

Fungal susceptibility testing was performed according to the guidelines of CLSI M27-A3 (CLSI, 2006). RPMI-1640 medium with L-glutamine buffered to $\mathrm{pH} 7$ with MOPS was added to each well of the microplates. The colonies were suspended in sterile saline, and the resulting suspension was adjusted to McFarland 0.5 density $\left(10^{6} \mathrm{CFU} / \mathrm{ml}\right)$. A working suspension was prepared by an 1:100 dilution followed by an 1:20 dilution of the stock suspension. $10 \mu \mathrm{l}$ of this suspension at $10^{3} \mathrm{CFU} /$ $\mathrm{ml}$ were added to the two-fold diluted solution of

Andriole V. T. (1999), The 1998 Garrod Lecture. Current and future antifungal therapy: new targets for antifungal agents. J. Antimicrob. Chemother. 44, $151-162$.

Arisoy M., Temiz-Arpaci O., Yildiz I., Kaynak-Onurdag F., Aki E., Yalcin I., and Abbasoglu U. (2008), Synthesis, antimicrobial activity and QSAR studies of 2,5-disubstituted benzoxazoles. SAR QSAR Environ. Res. 19, 589-612.

CLSI (formerly NCCLS) (2006), Reference method for broth dilution antifungal susceptibility testing yeast; approved standard, CLSI M27-A3. Clinical and Laboratory Standards Institute, Wayne, PA, USA.

CLSI (formerly NCCLS) (2008), Performance standards for antimicrobial susceptibility testing; 16th informational supplement, CLSI M100-S18. Clinical and Laboratory Standards Institute, Wayne, PA, USA.

Haansuu J. P., Klika K. D., Söderholm P. P., Ochaveranko V. V., Pihlaja K., Haahtela K. K., and Vuorela P. M. (2001), Isolation and biological activity of frankiamide. J. Ind. Microbiol. Biotechnol. 27, 62-66.

Moustafa M. A., Gineinah M. M., Nasr M. N., and Bayoumi W. A. (2004), Novel analogues of sydnone: synthesis, characterization and antibacterial evaluation. Arch. Pharm. (Weinheim) 337, 427-433.

Oksuzoglu E., Temiz-Arpaci O., Tekiner-Gulbas B., Eroglu H., Sen G., Alper S., Yildiz I., Diril N., AkiSener E., and Yalcin I. (2007), A study on the genotoxic activities of some new benzoxazoles. Med. Chem. Res. 16, 1-14.

Oksuzoglu E., Tekiner-Gulbas B., Alper S., TemizArpaci O., Ertan T., Yildiz I., Diril N., Sener-Aki E., and Yalcin I. (2008), Some benzoxazoles and benz- the compounds, and microplates were incubated for $24-48 \mathrm{~h}$ at $35^{\circ} \mathrm{C}$.

After incubation, the lowest concentration of the compounds that completely inhibited visible growth was determined and reported as minimum inhibitory concentration (MIC). Control wells contained all components, except the tested compounds, and all experiments were done in triplicate.

\section{Acknowledgements}

This work was supported by the Ankara University Research Fund (Grant No. 12B 3336001). The Central Laboratory of the Faculty of Pharmacy of Ankara University supported the acquisition of the NMR and mass spectra and elemental analyses of this work.

imidazoles as DNA topoisomerase I and II inhibitors. J. Enzyme Inhib. Med. Chem. 23, 37-42.

Prudhomme M., Guyot J., and Jeminet G. (1986), Semisynthesis of A23187 (calcimycin) analogs. IV. Cation carrier properties in mitochondria of analogs with modified benzoxazole rings. Antimicrobial activity. J. Antibiot. 39, 934-937.

Sarma H. K., Sharma B. K., and Tiwari S. C. (2003), A novel calcimycin antibiotic from Gram-positive actinomycete Frankia microsymbiont. Curr. Sci. 85, $1401-1403$.

Tekiner-Gulbas B., Temiz-Arpaci O., Yildiz I., and Altanlar N. (2007), Synthesis and in vitro antimicrobial activity of new 2-[ $p$-substituted-benzyl]5-[substituted-carbonylamino] benzoxazoles. Eur. J. Med. Chem. 42, 1293-1299.

Temiz-Arpaci O., Aki-Sener E., Yalçin I., and Altanlar N. (2002), Synthesis and antimicrobial activity of some 2 -[ $p$-substituted-phenyl]benzoxazol-5-yl-arylcarboxyamides. Arch. Pharm. (Weinheim) 335, 283-288.

Temiz-Arpaci O., Ozdemir A., Yalçin I., Yildiz I., Aki-Sener E., and Altanlar N. (2005), Synthesis and antimicrobial activity of some 5-[2-(morpholin-4-yl)acetamido] and/or 5-[2-(4-substituted piperazin-1-yl)acetamido]-2-( $p$-substituted phenyl)benzoxazoles. Arch. Pharm. (Weinheim) 338, 105-111.

Temiz-Arpaci O., Yildiz I., Ozkan S., Kaynak F., Aki-Sener E., and Yalçin I. (2008), Synthesis and biological activity of some new benzoxazoles. Eur. J. Med. Chem. 43, 1423-1431.

Yildiz-Oren I., Tekiner-Gulbas B., Yalcin I., TemizArpaci O., Aki-Sener E., and Altanlar N. (2004), Synthesis and antimicrobial activity of new 2-[p-substituted-benzyl]-5-[substituted-carbonyl-amino]benzoxazoles. Arch. Pharm. (Weinheim) 337, 402-410. 